\title{
Bibliographie stendhalienne générale, sous la direction de Victor Del Litto, coordonné et revue par Emanuele Kanceff
}

\section{Annalisa Bottacin}

\section{(2) OpenEdition}

Journals

\section{Edizione digitale}

URL: https://journals.openedition.org/studifrancesi/26466

DOI: $10.4000 /$ studifrancesi.26466

ISSN: 2421-5856

\section{Editore}

Rosenberg \& Sellier

\section{Edizione cartacea}

Data di pubblicazione: 1 avril 2007

Paginazione: 190-191

ISSN: 0039-2944

\section{Notizia bibliografica digitale}

Annalisa Bottacin, «Bibliographie stendhalienne générale, sous la direction de Victor Del Litto, coordonné et revue par Emanuele Kanceff», Studi Francesi [Online], 151 (LI | I) | 2007, online dal 30 novembre 2015, consultato il 23 novembre 2021. URL: http://journals.openedition.org/studifrancesi/26466 ; DOI: https://doi.org/10.4000/studifrancesi.26466

Questo documento è stato generato automaticamente il 23 novembre 2021.

\section{cc) (†) $\odot$}

Studi Francesi è distribuita con Licenza Creative Commons Attribuzione - Non commerciale - Non opere derivate 4.0 Internazionale. 


\title{
Bibliographie stendhalienne générale, sous la direction de Victor Del Litto, coordonné et revue par Emanuele Kanceff
}

\author{
Annalisa Bottacin
}

\section{NOTIZIA}

Aa. Vv., Bibliographie stendhalienne générale, sous la direction de Victor DEL LITTO, coordonné et revue par Emanuele KANCEFF, Moncalieri, C. I. R. V. I., «Biblioteca del Viaggio in Italia», n. 30, 2005, t. VI, «Bibliografie», pp. 2460-3024.

1 In attesa del volume degli Indici, che senza dubbio alcuno ne sveltirà la consultazione, esce il sesto volume, pubblicato dalle Edizioni del C.I.R.V.I., della Bibliographie stendhalienne générale, voluta dal compianto Victor DEL LITTO con la collaborazione di Emanuele KANCEFF, presenza determinante nella stesura di quest'opera, così definita dall'eminente stendhaliano: «L'ouvrage que j'ai l'honneur et le plaisir de présenter est un recueil d'un genre particulier: il n'est pas, en effet, un livre qu'on feuillette ou qu'on lit d'un bout à l'autre, mais un ouvrage qu'on consulte, un peu dans le genre des encyclopédies, mais, alors que les encyclopédies n'ont pas de personnalité propre, la Bibliographie stendhalienne générale, de par son titre, porte la marque de son identité et de sa destination... La bibliographie est un révélateur». (I, p. 11). Anche questo, come i precedenti repertori bibliografici degli studi stendhaliani inerenti Francia, Italia e Spagna (pp. I-V), distingue in un certo numero di sezioni le opere di Stendhal, le loro traduzioni, gli inediti e le vendite, quindi gli articoli, i saggi e note varie, per rendere più chiara e semplice la loro consultazione, allo scopo di fornire uno strumento di lavoro preziosissimo per tutti gli studiosi dello scrittore grenoblese. Pur tuttavia, come ben comprese Del Litto, una bibliografia per essere la più completa possibile deve 
spaziare anche in quei paesi da cui, per difficoltà linguistiche o a causa di indubbie distanze, il prodotto critico-letterario tarda ad uscire e di conseguenza a diffondersi tra gli addetti ai lavori.

In effetti in questo sesto volume vengono ad aggiungersi, con il medesimo criterio di divisione in sezioni, i contributi delle altre aree europee e altresì del Giappone e degli Stati Uniti. Questo l'ordine: Allemagne (1817-1993) a cura di Christa RIEHN (pp. 2466-2657), seguito da États-Unis (1820-1974) realizzato da Jules C. ALCIATORE e Maud SAINT-LEGER WALTHER (pp. 2659-2719); Finlande (1910-1965) curato da Sylvia NEHRING, prima bibliografia di Stendhal in questo paese (pp. 2723-2725); Grèce (1925-1973) proposto da Maria maCropoulou (pp. 2727-2734); Hongrie (1982-1983) presentato da Eva MARTONYI (pp. 2737-2739). Seguono gli studi giapponesi, che si segnalano per copiosità e importanza: Japon (1911-1996) curato da Kosei KURISU (pp. 2740-2924). Quindi Russie redatto da Tatiana MULLER KOTCHETKOVA e A. MIKAILOV (quest'ultimo relativamente agli anni 1960-62) (1933-1983) (pp.2925-2967); Suède (1902-1994) realizzato da Börje SCHLYTER (pp. 2969-2977); Turquie a cura di Köse NACI (pp. 2978-2984), il quale precisa in una nota che i reperimenti bibliografici su Stendhal e la sua opera sono in parte ancora incompleti e presenta solo l'elenco delle traduzioni dal 1941 al 1971. Segue l'Yougoslavie (1897-1961) proposto da Dusan MILACIC (pp. 2985-2997); in un breve profilo il curatore evidenzia come gli studi stendhaliani siano iniziati solo quarantaquattro anni dopo la scomparsa di Henri Beyle e nessuna sua opera sia stata ancora tradotta. Nel XX secolo, pur lentamente, vi è stato un avvio alla scoperta del grenoblese, e a partire dal 1919 iniziano i primi rilevanti contributi. Segue a chiusura del corposo volume la Table du sixième volume (pp. 2999-3024).

Quest'alta circolazione d'idee e contenuti, voluta da Del Litto, contrassegna, accanto all'utilità dell'oggetto, il tratto distintivo di Stendhal uomo e scrittore nell'universo delle Lettere, e consente ancora una volta di evidenziare quella specificità che rende immortale il genio, oltre ogni luogo ed ogni tempo. 